\title{
LAND USE/LAND COVER CHANGE PREDICTION USING MULTI-TEMPORAL SATELLITE IMAGERY AND MULTI-LAYER PERCEPTRON MARKOV MODEL
}

\author{
H.T.T. Nguyen ${ }^{1}$, T.A. Pham ${ }^{2}$, M.T. Doan ${ }^{1}$, P.T.X. Tran ${ }^{1}$ \\ ${ }^{1}$ Dept. of Forest Resource and Environment management, Tay Nguyen University - huongthanh.frem@ttn.edu.vn, \\ doanminhtrungmt12@gmail.com, phantran8883@gmail.com \\ ${ }^{2}$ Department of Agriculture and Rural Development Dak Nong - phamtuanhln@gmail.com
}

\begin{abstract}
Commission IV
KEYWORDS: Land use/ land cover change, Landsat satellite images, Markov-Chain (MC), Multi-Layer Perceptron Neutral Network (MLP-NN), and prediction.

ABSTRACT:

This paper aims to predict the trend of land use land cover (LULC) changes in Dak Nong province over time. Data from Landsat images captured in 2009, 2015, and 2018 was employed to analyze and predict the spatial distributions of LULC categories. The Random Forest (RF) was adopted to classify the images into ten different LULC classes. Besides, integration of Multi-Layer Perceptron Markov Neural Network (MLP-NN) with Markov Chain (MC) was applied to predict the future LULC changes in the region based on the change detection over the previous years. For all classified images, overall accuracy $(\mathrm{OA})$ ranged from $77.35 \%$ to $84.55 \%$ with kappa (K) coefficient index ranging from 0.75 to 0.8 . The results revealed that the annual population growth together with social-economic development was regarded as major drives for land conversion in the area. The predicted map showed a significant decrease trend in the forest classes by 2025 , accounting for 23 thousand ha. However, residential areas, rubber, and agricultural land classes are predicted to rise to $460 \mathrm{ha}, 3,000 \mathrm{ha}$, and 20,000 ha, respectively. The simulated model and calibrated area data may be a vital contribution to sustainable development efforts of the local based on the dynamics of LULC and future LULC change scenarios. Overall, ascertaining the complex interface related to changes in land use and its major drivers over time provides useful information predict to explore the future trend of LULC changes, establish alternative land-use schemes and serve as guidelines for urban planning policymakers.
\end{abstract}

\section{INTRODUCTION}

Changes in land use land cover (LULC) relevant to anthropogenic activities have significantly changed the biological and geochemical processes on earth contributing to global environmental concerns (Prakasam, 2010; Firozjaei et.al., 2018). Information about LULC changes is applicable for natural resources management and recommendations for local socioeconomic growth in a specific area. Thus, monitoring, analyzing, and understanding the conversion of LULC changes are needed to provide precise and timely information on current land use characteristics and changes for local authorities regardless of sustainable development.

Remote sensing (RS) and geographic information systems (GIS) have been popularly adopted as essential and useful tools in obtaining accurate spatial data of LULC and quantifying the alternations of spatial data. The application of the CA-Markov model in predicting LULC changes has conveniences due to its powerful replication, and it is used for mapping LULC changes providing good performance regardless of dynamic modeling efficiently; high productivity with data, simple analysis; and capacity to detect transitions between land use classes (Sang et al., 2011; Chan et al., 2018). A study on prediction of future LULC scenarios for urban growth modeling between the Multilayer Perceptron-Markov (MLP-MC) and the CA-Markov conducted in Atakum, Samsun, Turkey revealed that the MLPMC model produced results outperformed the CA-Markov regardless of LULC change simulation (Ozturk, 2015). Also, there is a study of replication on simulating the LULC map conducted in Dhaka region through three different models:
Stochastic Markov (St_Markov)", CA-MC, and MLP-MC (Ahmed, Ahmed, 2012). The results illustrated that the MLPMarkov model yielded the most performance in monitoring and predicting the land-use dynamics.

Dak Nong province has a high diversity of natural forest resources in the Central Highlands of Vietnam. In recent years, Dak Nong has experienced a burst in population growth resulting in high demand for agricultural land and urban expansion causing natural forest degradation. Besides, the technical guidelines in natural resource management mechanism have exposed issues such as deforestation, encroachment led to forest cover declined in the province (Müller, 2004). Thus, there is a crucial need for analysis of LULC change over time and prediction on the future trend of land use transformation based on multi-temporal satellite imagery. In this study, integration of the MLP NN with the Markov model manipulated in the Land Change Modeler (LCM) tool through IDRISI TerrSet software was employed to detect temporal changes and model the future spatial distribution of different land uses.

\section{MATERIALS AND METHODS}

\subsection{Study Area}

Dak Nong province where is a part of the subtropical monsoon climate zone characterized by humid tropical highland climate and dry-hot southwest monsoon, located in the Central Highlands of Vietnam (Figure 1). The mean elevation is about 650 meters above the level of the sea with an annual average temperature of

\footnotetext{
${ }^{1}$ Corresponding author
} 
24 Degree Celsius. The region consists of two distinct periods per year including the rainy and dry seasons. Its average annual rainfall is $2,500 \mathrm{~mm}$ (the rainy season represents over 90 percent of rainfall all year round). The study area covers approximately $6.516 \mathrm{~km}^{2}$ including various types of LULC with substantial fragmentation.

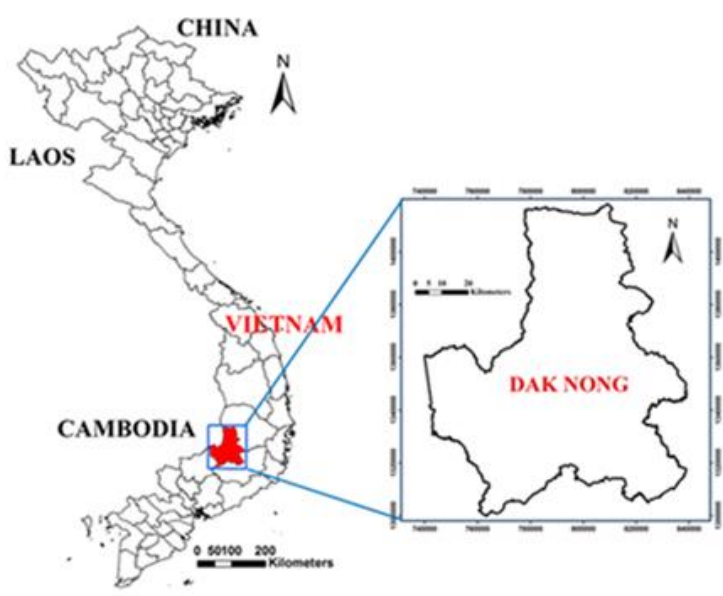

Figure 1. The study area of Dak Nong province

\subsection{Data Acquisition and Preparation}

The research used USGS Landsat 5, Landsat 8 SR (Surface Reflectance Tier 1), and remote sensing data collections available on Google Earth Engine (GEE). These satellite images were captured by the years 2009, 2015, and 2018. Landsat 5 and Landsat 8 SR atmospherically corrected surface reflectance from the sensors of Landsat 5 ETM and Landsat 8 OLI/TIRS, respectively. A resampling process of the thermal infrared (TIR) band was initially chosen at $120 \mathrm{~m} /$ pixel resolution. Landsat $8 \mathrm{SR}$ scenes contain four visible bands (B1, B2, B3, B4): orthorectifications of surface directional reflectance was applied to one near-infrared (VNIR: B5) and two short-wave infrared (SWIR: B6, B7) bands, while two thermal infrared (TIR: B10, B11) bands were processed to brightness temperature ortho-rectifications (Google Developers: Earth Engine Data Catalog). Landsat 5 SR data was corrected using LEDAPS (Department of the Interior U.S. Geological Survey. 2019a); LaSRC (Department of the Interior U.S. Geological Survey, 2019b) was used to correct Landsat $8 \mathrm{SR}$, and both included a mask for clouding and shadowing, through CFMASK (Foga et al., 2017), as well as a saturation mask per-pixel. The multi-spectral bands of Landsat 5 SR (included Blue (B1), Green (B2), Red (B3), NIR (B4), SWIR 1 (B5), TIR (B6); SWIR 2 (B7)) and NDVI and the multi-spectral bands of Landsat 8 SR (Ultral Blue (B1), Blue (B2), Green (B3), Red (B4), NIR (B5), SWIR 1 (B6), SWIR 2 (B7), TIR 1 (B10), TIR 2 (B11)) and NDVI were employed in the current study.

As three periods were considered in this study, including 2010, 2015, and 2018, Landsat 5 and 8 SR data were used to ensure that the entire area was covered and the effects of clouds were eliminated. Accordingly, the Landsat image data sets were divided into four temporal periods including i) a collection of Landsat 5 SR scenes in 2009 and 2010; ii) a collection of Landsat 8 SR scenes in 2014 and 2015, and iii) a collection of Landsat 8 SR scenes in 2017 and 2018. The detailed data of the satellite images are shown in Table 1.

\begin{tabular}{|c|c|c|c|c|}
\hline $\begin{array}{c}\text { Landsat } \\
\text { data }\end{array}$ & Year & $\begin{array}{l}\text { Acquisition } \\
\text { date }\end{array}$ & $\begin{array}{c}\text { No } \\
\text { images } \\
\text { involved }\end{array}$ & $\begin{array}{l}\text { No. } \\
\text { bands }\end{array}$ \\
\hline
\end{tabular}

\begin{tabular}{|c|c|c|c|c|}
\hline $\begin{array}{l}\text { Landsat } 5 \\
\text { SR Tier } 1 \\
\end{array}$ & $\begin{array}{l}2009- \\
2010\end{array}$ & $\begin{array}{c}01 / 01 / 2009- \\
12 / 31 / 2010 \\
\end{array}$ & 84 & 08 \\
\hline $\begin{array}{l}\text { Landsat } 8 \\
\text { SR Tier } 1\end{array}$ & $\begin{array}{l}2014- \\
2015\end{array}$ & $\begin{array}{l}01 / 01 / 2014 \\
12 / 31 / 2015 \\
\end{array}$ & 143 & 10 \\
\hline $\begin{array}{l}\text { Landsat } 8 \\
\text { SR Tier } 1\end{array}$ & $\begin{array}{l}2017- \\
2018\end{array}$ & $\begin{array}{l}01 / 01 / 2017 \\
12 / 31 / 2018\end{array}$ & 128 & 10 \\
\hline
\end{tabular}

Table 1. Information on Landsat satellite data used in the study

On the other hand, the digital data including existing land use/forest maps (collected from relevant departments of Dak Nong), training field sample points; and Google Earth were used as training sites to classify the given satellite imageries into various LULC categories.

\subsection{Selection of Drivers}

The driver variables are understood as factors that are the main contributors to LULC change (Nguyen, Ngo, 2018). The selected factors were based on the reliable source of data and the explanatory capacity of the data that can display spatially explicit variables (Khoi, Murayama, 2010). Driver variables affecting LULC change include natural factors (e.g. topography, precipitation, and slope) and social factors (e.g. population density and policy schemes). However, due to the lack of available information relevant to policies occurring in the study area, we only collected data associated with the natural drivers including elevation, slope, and distance to rivers or streams. On the other hand, the group of social elements includes the length to road and residential areas elements required decentralization from the local forest management units since these factors have affected accessing and encroachment to forest resources.

\subsection{Training and Validation Data}

Within the study area, the ten different types of LULC were discriminated: (1) Evergreen broadleaved forest; (2) Semievergreen forest (the forest that consists of a mixture of evergreen and deciduous dipterocarp tree species); (3) Dipterocarp forest; (4) Plantation forest; (5) Mature rubber ( $\geq 3$ years old) (6) Perennial industrial plants; (7) Cropland; (8) Residential area; (9) Water surface; and (10) other types of land (including grassland, shrubs, bare land, unplanned land, abandoned land, and so on). Few studies have been published on the effectiveness of using collected samples from the integration of sources including the ground truth data, Landsat images with a high spatial resolution derived from Google Earth (GE), and reference maps (Sothe et al., 2017; Teluguntla et al., 2018). These authors both achieved excellent outputs and proved the importance of the sampling process in evaluating the classification accuracy results.

The dataset used in the classification and validation process was collected from different sources such as i) ground truth points collected in the field; ii) fine resolution and very fine resolution images obtained from GE and iii) the existing Dak Nong Forest Inventory/LULC Maps. Besides, the sample areas were directly collected according to the given Landsat satellite images where the samples are discriminated against others based on the user's experience.

\subsection{Methods}

2.5.1 Image Classification: The Random Forest (RF) algorithm proposed by Breiman (2001) was adopted to categorize Landsat images into LULC maps. Optimal values of the algorithm such as mtry, ntree, and variable importance were selected as described in previous studies (Nguyen et al., 2018, 2020). As regards the accuracy assessment, the matrix is considered the most effective method for evaluating 
classification accuracy (Congalton, Green, 2019). Accordingly, the matrix confusion was computed statically, and this method was used to evaluate the accuracy of the classified images based on parameters: Overall Accuracy (OA), Kappa coefficient (K), Producer Accuracy (PA), and User Accuracy (UA). Classification accuracy assessment was implemented using the method of randomly dividing the sample data set into two independent parts, with $60 \%$ of the data used for the classification and the remaining $40 \%$ of the sample employed to evaluate the accuracy of the model.

2.5.2 LULC Change Detection Analysis: Employing LCM acquires different temporal maps, and LULC maps of the year 2009, 2015, and 2018 were used to detect the changes of LULC classes. This allowed us to comprehend the transitional trend and contribution between LULC classes over time.

2.5.3 LULC Change Prediction: The study used the integration of MLP with the MC to forecast the future LULCC in 2018 and 2025 .

The MLP-MC model displayed in the LCM tool includes the following steps: a) change detection, b) transition model and c) change anticipation (Eastman, 2012; Losiri et al., 2016).

i. Change analysis: Two LULC maps were used to examine the primary transformations which are modeled independently as sub-model in the following stage.

ii. Modeling a transition probability: To clarify the driver variables, Cramer's V, a prominent quantitative measurement which indicates a number ranged from 0 to 1 implying how strongly relevant factors are associated with two categorical maps (Ahmed, Ahmed, 2012; Nouri et al., 2014). As noted from the literature, if the variable has a Cramer's V value of 0.15 or greater, it implies that the correlation is reliable. In the case of a value reaching above 0.4 , the combination is good. Once the explanation of components was investigated in individual land conversion, the LCM accepted MLP to create the transitions of LULC maps. The MLP algorithm iteratively alters the associated weights among the nodes following different layers in a way that the error between the calculated data and their expected outcomes is diminished to improve accuracy (Dadhich, Hanaoka, 2010).

As performed in each sub-model of land transition, the MLP randomly develops a dataset of samples that have not shown the transition. Accordingly, each sub-model includes one transition and two samples of classes being provided. The MLP generates a neural network based on samples and driver variables corresponding with a connected network consisting of associated weights. The collected cells then are disjoined into two clusters including a sample set of 50 percent using for training and the remaining proportion for validation (Mozumder, Tripathi, 2014; Mishra et al., 2014; Mozumder et al., 2016). This process aims to generate the correlation between transition probability and driving forces. Therefore, the calculated weight helps to minimize the mistake to increase accuracy. Once the accuracy is above $80 \%$ or achieves the maximum repetition, the probability of transitional maps of each sub-model obtains the appropriateness of LULC categories over the predicted time.

iii. LULC change prediction: The process of forecasting change is implemented in the LCM to examine the quantity of the future LULC in a given temporal period simulated by MC. The first output is a hard prediction model resulted from a projected LULC map according to the process of land allocation. A soft prediction is the second output in which a comprehensive vulnerability map is conducted corresponding with the set of transitions. Overall, the default values ranged from 0 to 1 are the outputs of the soft prediction (Megahed et al., 2015).

To quantify the changes occurring on the future land use types, the MC simulation was modeled (Eastman, 2016). It uses the knowledge based on the transitional possibility between the first time point and the last one to identify the dynamic trend among various LULC categories. The simulated model process randomly generates a land-use conversion matrix and a matrix transformation table to forecast the future land use modification. Therefore, the MC in LCM was employed to create a transition probability matrix for 2018 until 2025 (Muller, Middleton, 1994; Dadhich, Hanaoka, 2010; Chen et al., 2018)

By using MLP-NN analysis, the weights of the transition were determined according to the matrix of transition probabilities in MC for the forecasting of future LULC changes (Ahmed, Ahmed, 2012; Eastman, 2016). The final land cover maps of 2018 and 2025 were simulated through the Markov chain module integrated with IDRISI corresponding information from the MLP-NN.

2.5.4. Model Validation: The model validation process was implemented through an accurate comparison between predicted LULC maps and classified images in 2009, 2015, and 2018. The study employed the cross-tabulation in IDRISI regarding performance evaluation of the model to calculate OA from each predicted LULC category. Also, the K index was considered to measure the success of the simulation. Once the kappa index is acceptable, the LULC in 2025 will be predicted (Nasiri et al., 2019).

\section{RESULTS AND DISCUSSIONS}

\subsection{Accuracy Assessment}

Overall, OA for all classified images from three temporal periods (2009, 2015, and 2018) ranged from $77.35 \%$ to $84.55 \%$, with K indices ranging from 0.75 to 0.81 . It is noticeable that the 2015 LULC map had the highest accuracy of OA $(84.55 \%)$ with K reaching at 0.81 . While the lowest $\mathrm{OA}$ of $77.35 \%$ was achieved for the 2009 LULC corresponding K of 0.75 . The figure for PA and UA among LULC types also presented above $60 \%$.

\subsection{LULC Change Detection}

This study compared three maps (2009-2015-2018) and produced a statistic analysis of LULC changes in hectares and percentages over time presented in Table 2.

It is seen from Figure 2. that dramatic changes and transformations were found between ten LULC classes over the years from 2009 to 2018 . The dominant variations and transitions figured out mainly among evergreen, dipterocarp forests, rubber, and industrial plants. 


\begin{tabular}{|c|c|c|c|c|c|c|}
\hline \multirow{2}{*}{ LULC classes } & \multicolumn{2}{|c|}{2009} & \multicolumn{2}{|l|}{2015} & \multicolumn{2}{|c|}{2018} \\
\hline & Area (ha) & $\%$ & Area (ha) & $\%$ & Area (ha) & $\%$ \\
\hline EverGreen & $221,708.61$ & 34.00 & $189,227.34$ & 29.02 & $178,062.03$ & 27.30 \\
\hline Semi-EverGreen & $17,856.90$ & 2.74 & $22,467.87$ & 3.45 & $23,781.87$ & 3.65 \\
\hline Dipterocarp & $32,057.28$ & 4.92 & $21,374.82$ & 3.28 & $16,035.21$ & 2.46 \\
\hline Plantation & $6,533.28$ & 1.00 & $6,974.46$ & 1.07 & $8,037.00$ & 1.23 \\
\hline Rubber & $3,601.08$ & 0.55 & $18,740.07$ & 2.87 & $22,750.47$ & 3.49 \\
\hline Industrial Plants & $270,950.31$ & 41.55 & $314,437.14$ & 48.21 & $320,168.70$ & 49.09 \\
\hline Crop Land & $24,607.08$ & 3.77 & $26,953.11$ & 4.13 & $29,530.80$ & 4.53 \\
\hline Residential & $4,478.22$ & 0.69 & $6,163.83$ & 0.95 & $6,320.34$ & 0.97 \\
\hline Water Surface & $2,897.19$ & 0.44 & $9,244.71$ & 1.42 & $10,332.09$ & 1.58 \\
\hline Others & $67,473.09$ & 10.35 & $36,579.69$ & 5.61 & $37,144.53$ & 5.70 \\
\hline Total & $652,163.04$ & 100.00 & $652,163.04$ & 100.00 & $652,163.04$ & 100.00 \\
\hline
\end{tabular}

Table 2. Area of LULC categories over years (ha)

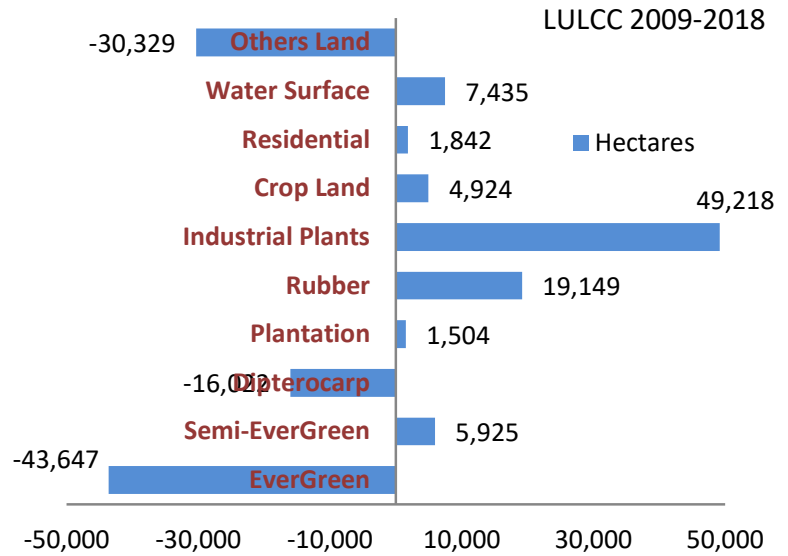

Figure 2. Land Use/Land Cover Net Changes in hectares from 2009 to 2018

To sum up, for forest cover classes, the area of natural evergreen forest and dipterocarp forest decreased over the years. In contrast, the area of semi-evergreen and planted forests gradually increased over periods. For non-forest cover categories, the area of industrial plants, cropland, residential area, and water surface are classes with the increasing area over the years due to economic, social development, and population growth, while other types of land are volatile but the trend decreases over periods.

Human activities directly impact natural forests such as logging, agricultural expansion, or infrastructure, hydroelectricity and road development. However, the main driver of deforestation was the conversion of forests to commercial agriculture products such as coffee, pepper, rubber, cassava (Kissinger, 2020). According to a report from the Ministry of Natural Resources and Environment (2014), poor forest transformation into rubber plantations has considerably resulted in a reduction of dipterocarp forests including a semi-deciduous forest in the Central Highlands and other natural forests. The Central Highlands and the southeast of Vietnam are regarded with the highest area of natural forests, and spontaneous population movement from different places of the country. It is noticeable that free migration to the region reduced significantly by 2006 compared to 2005 . However, it showed an upward again in the two following years, and this trend has continuously increased until the present. Population movement at the national scale arising with forest degradation worthy considered in the Highland region. For many domestic migrants, particularly the northern ethnic minorities, their livings highly depend on exploited products such as timbers, firewood, herbs, and orchards from natural forests. Hence, population growth has led to an increase in land-use for cultivating, and grazing contributed to deforestation at an alarming rate. Besides, economic development has caused overexploitation of natural resources leading to biodiversity degradation and declined ecological functions of native forests. Though there have been regulations of forest protection and management introduced to the communities to limit illegal forest operations by the government, the current issues of illegal logging are increasingly occurring in the whole region in general (Ministry of Natural Resources and Environment, 2014).

\subsection{LULCC Prediction with CA-Markov and Validation}

The MLP - NN and MC were used to simulate the LULC modifications pattern in Dak Nong for 2018 based on information from driver variables, transition potential maps, and transition probability matrix. A comparison was implemented between the reference and simulated LULC map to validate the LULC prediction in 2018 by $\mathrm{K}$ variations. The model validation was presented in Figure 3. The results show how similarity between predicted and actual LULC maps of 2018 based on 4 parameters including Kno (kappa for no ability), Klocation (Kappa for location) and Kstandard (Kappa index).

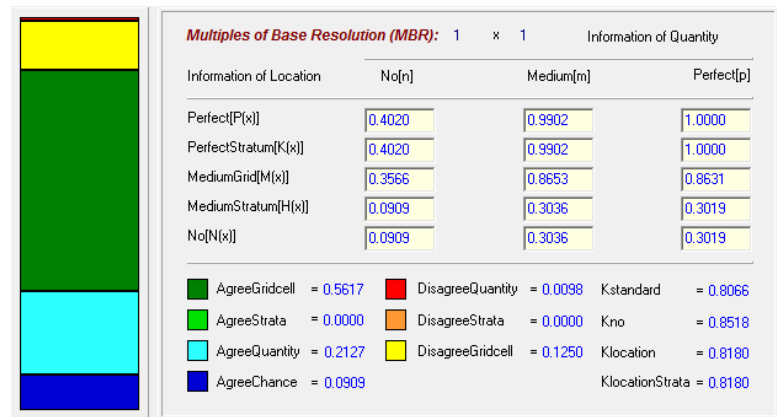

Figure 3. Agreement between classified LULC and predicted LULC map in 2018

As illustrated above, the MLP-MC prediction model achieved a $\mathrm{K}$ value $>0.80$. $\mathrm{K}$ coefficients usually range from 0 to 1 (Cicchetti, Feinstein, 1990). If $\mathrm{K}$ ranging from 0.60 to 0.80 means moderate agreement, while a $\mathrm{K}$ value between 0.80 and 1 implies a good agreement. Here, the $\mathrm{K}$ index is more than 0.80 which illustrates a significant agreement between the simulated map and the classified map of 2018. This value is a very high degree of discrimination and similarities between the two LULC maps implying that the results are satisfactory (Landis, Koch, 1977). 


\begin{tabular}{|c|c|c|c|c|}
\hline \multirow{2}{*}{ LULC ccategory } & \multirow{2}{*}{$\begin{array}{l}\text { Classified map } \\
\text { Area (ha) }\end{array}$} & \multirow{2}{*}{$\begin{array}{l}\text { Predicted map } \\
\text { Area (ha) }\end{array}$} & \multicolumn{2}{|c|}{ Difference } \\
\hline & & & Area (ha) & Percent $(\%)$ \\
\hline EverGreen & $178,062.03$ & $176,208.12$ & $1,853.91$ & 1.04 \\
\hline Semi-EverGreen & $23,781.87$ & $21,451.32$ & $2,330.55$ & 9.80 \\
\hline Dipterocarp & $16,035.21$ & $17,629.74$ & $-1,594.53$ & -9.94 \\
\hline Plantation & $8,037.00$ & $6,783.84$ & $1,253.16$ & 15.59 \\
\hline Rubber & $22,750.47$ & $21,818.70$ & 931.77 & 4.10 \\
\hline Industrial Plants & $320,168.70$ & $329,285.97$ & $-9,117.27$ & -2.85 \\
\hline Crop Land & $29,530.80$ & $27,521.10$ & $2,009.70$ & 6.81 \\
\hline Residential & $6,320.34$ & $6,986.34$ & -666.00 & -10.54 \\
\hline Water Surface & $10,332.09$ & $10,566.63$ & -234.54 & -2.27 \\
\hline Others & $37,144.53$ & $33,911.28$ & $3,233.25$ & 8.70 \\
\hline Total & $652,163.04$ & $652,163.04$ & & \\
\hline
\end{tabular}

Table 3. Comparison of classified and simulated LULC maps in 2018

The Disagree Grid cell and Disagree Quantity indices have significance in predicting the LULC changes (Wang et al., 2016). Our findings indicated that the Disagree Grid cell $=0.1250$ is greater than Disagree Quantity $=0.0098$, this means that the precision for the correct prediction of the model is relatively high. Therefore, it is more likely to forecast the variations of LULC for quantifying than considering the location. Besides, the Kno index is regarded as the most important parameter which is used for evaluating the overall of a model (Pontius, 2000). As shown in Figure 3, the value of Kno is approximately 0.85 , which means that the results of the MLP_Markov forecasting model are acceptable and continuous the prediction LULCC until 2025 for Dak Nong province.

It is evident from Table 3 that there is an insignificant difference in the area between the simulated and the observed LULC maps in 2018. The best agreement with a different rate is less than 5\% including evergreen forest, water surface, industrial plants, and rubber. Whereas the worst agreement is the plantation class with a different percentage from actual LULC reaching $15.59 \%$, the following classes were semi-evergreen, others, and cropland.

The LULC map for the year 2025 presented in Figure 4 was modeled based on the LULC maps in 2015 and 2018. The results of land-use change prediction are summarized in Table 4.

\section{Projected LULC 2025}

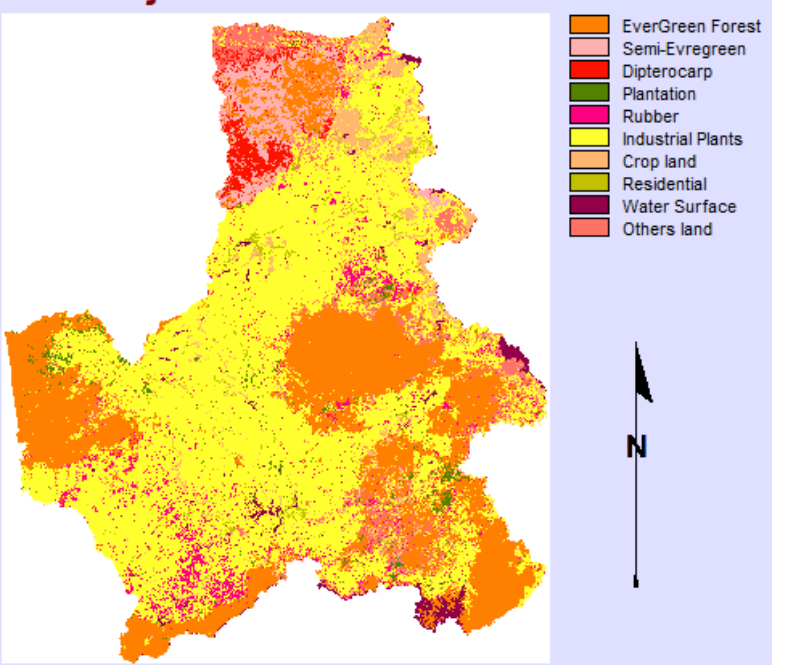

Figure 4. MLP_Markov model projected the LULC scenario of Dak Nong 2025.
Yirsaw et al., (2017) suggested that the trend of LULC in a region shows the changes happening in the past years being more likely to occur in the following years. As illustrated in Figure 5, the predictive results show that the natural forest categories represent a decrease continuously in the future. Of the area that changes from 2018 to 2025, the major changes concern the natural forest areas, with a predicted decrease of more than 23,000 ha, equivalent to about $10.28 \%$ of the total forested area. Particularly, the evergreen forest is more likely to reduce more than 15,500 ha. Concerning semi-evergreen and dipterocarp forests, there is a clear tendency to reduce more than 7,600 ha. In contrast, agricultural land types consisting of cropland and rubber will see its importance continue to increase by about 20,000 ha. The remaining LULC types will expand continuously until 2025, where the plantation type is predicted to rise approximately 530 ha $(6.61 \%)$, and residential will increase by about 460 ha $(7.3 \%)$. It is recognizable that the decline in the natural forests may be due to population growth, the expansion of residential areas, and the demand for agricultural land increases. Moreover, the transition of a natural forest area into other land-use types such as grasslands, bare land, shrubs (3,000 ha) is also the reason for the decrease of forest area. 


\begin{tabular}{|c|c|c|c|c|}
\hline \multirow{2}{*}{ LULC category } & \multirow{2}{*}{$\begin{array}{r}2018 \\
\text { Area (ha) }\end{array}$} & \multirow{2}{*}{$\begin{array}{r}2025 \\
\text { Area (ha) }\end{array}$} & \multicolumn{2}{|c|}{ Predicted change } \\
\hline & & & Area (ha) & Percent (\%) \\
\hline EverGreen & $178,062.03$ & $162,527.76$ & $-15,534.27$ & -8.72 \\
\hline Semi-EverGreen & $23,781.87$ & $20,979.63$ & $-2,802.24$ & -11.78 \\
\hline Dipterocarp & $16,035.21$ & $11,152.08$ & $-4,883.13$ & -30.45 \\
\hline Plantation & $8,037.00$ & $8,568.36$ & 531.36 & 6.61 \\
\hline Rubber & $22,750.47$ & $25,759.89$ & $3,009.42$ & 13.23 \\
\hline Industrial Plants & $320,168.70$ & $336,322.44$ & $16,153.74$ & 5.05 \\
\hline Crop Land & $29,530.80$ & $33,366.51$ & $3,835.71$ & 12.99 \\
\hline Residential & $6,320.34$ & $6,780.60$ & 460.26 & 7.28 \\
\hline Water Surface & $10,332.09$ & $10,093.32$ & -238.77 & -2.31 \\
\hline Others & $37,144.53$ & $36,612.45$ & -532.08 & -1.43 \\
\hline Total & $652,163.04$ & $652,163.04$ & & \\
\hline
\end{tabular}

Table 4. Predicting area change of LULC in the period of 2018-2025

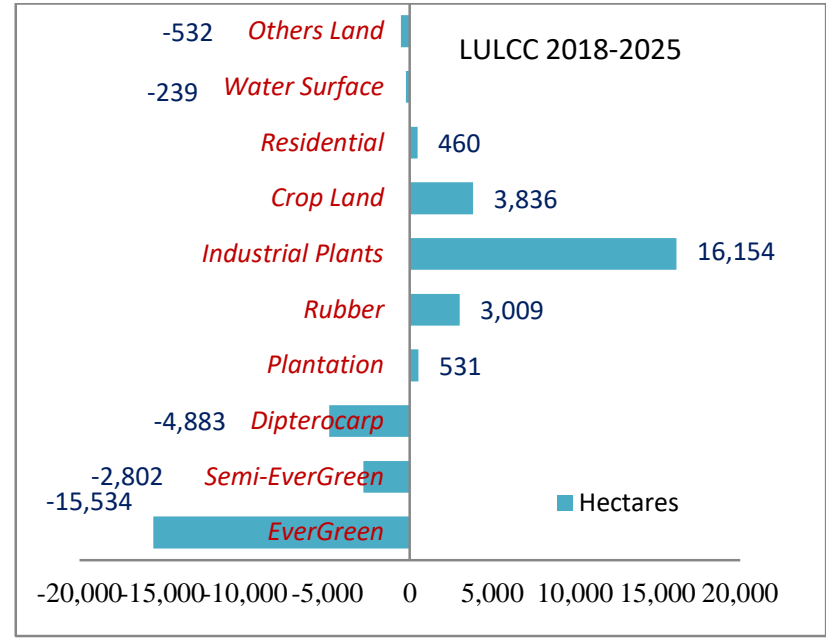

Figure 5. The change prediction in hectares of LULC classes from 2018 to 2025

\section{CONCLUSIONS}

Based on the LULC analysis obtained for the year 2009, 2015, and 2018 in Dak Nong, the classification results showed that the OA of LULC maps achieved from 77.35 to $84.55 \%$ with kappa varying from 0.75 to 0.81 . From this study, the findings revealed that the majority of land conversion in Dak Nong is natural forests to residential areas and agricultural land since the province experienced an increase in population as well as socialeconomic growth.

The simulation of LULCC in the year 2018 and 2025 using an integration of the MLP-MC resulted in high accuracy. The findings revealed that in 2018 the predicted LULC maps show reliable results with a significant agreement compared to the actual LULC maps. The simulation illustrates that the 2025 projected map indicates the trend observed from 2009 to 2018 , revealing that the natural forest area will continue to decrease by more than 23 thousand ha. By contrast, rubber, residential area, and agricultural land are predicted to increase by approximately $460 \mathrm{ha}, 3000 \mathrm{ha}$, and 20,000 ha, respectively. The findings from this study suggested that the observed continuous decrease in the natural forest area calls for concern which has caused pressures on the natural forest resources contributing to the high risk of global climate change. The modeled results also indicate that the current forest protection and management mechanisms did not very effectively work in the province. Therefore, findings may be useful and significant information for the local government to promote more effective policies regarding sustainable development and management of natural resources.

\section{ACKNOWLEDGEMENTS}

This work is a part of the research project within the PEER program (Partnerships for Enhanced Engagement in Research), sponsored by USAID. The authors would like to thank the sponsor and all of the people involved in the field data collection for classification and validation.

\section{REFERENCES}

Ahmed, B., Ahmed, R., 2012: Modeling urban land cover growth dynamics using multi-temporal satellite images. A case study of Dhaka, Bangladesh. ISPRS International Journal of GeoInformation, 1(1), 3-31.

Breiman, L., 2001. Random Forests. Machine Learning, 45(1), pp.5-32. doi:10.1023/A:1010933404324.

Chen, L., Sun, Y., Sajjad, S., 2018: Monitoring and predicting land use and land cover changes using remote sensing and GIS techniques. A case study of a hilly area, Jiangle, China. PloS one, 13(7), e0200493. doi:10.1371/journal.pone.0200493.

Cicchetti, D. V., Feinstein, A. R., 1990: High agreement but low kappa: II. Resolving the paradoxes. Journal of clinical epidemiology, 43(6), 551-558.

Congalton, R. G., Green, K., 2019: Assessing the accuracy of remotely sensed data: Principles and Practices (3rd edition). Boca Raton FL 33486-2742. CRC press.

Dadhich, P. N., Hanaoka, S., 2010. Markov method integration with multi-layer perceptron classifier for simulation of urban growth of Jaipur City: In 10th WSEAS/IASME international conference on electric power systems, high voltages, electric machines, Iwate Prefectural University, Japan (pp. 118-123) (pp. 118-123).

Department of the Interior U.S. Geological Survey, 2019a. Landsat 4-7 surface reflectance (LEDAPS) product guide. LSDS-1370. Version 2.0 (accessed on 15 July 2019).

Department of the Interior U.S. Geological Survey, 2019b. Landsat 8 surface reflectance code (LASRC) product guide. LSDS-1368. Version 2.0 (accessed on 18 July 2019). 
Google Developers: Earth Engine Data Catalog. Available online: https://developers.google.com/earth-engine/datasets (accessed on 29 March 2019).

Eastman, J. R., 2012: IDRISI Selva Tutorial, Manual Version 17. IDRISI Production, Clark Labs-Clark University, Worcester, 45.

Eastman, J. R., 2016: TerrSet Manual - Geospatial Monitoring and Modeling System. Clark Labs Clark University: Worcester, MA, USA. p. 470.

Firozjaei, M. K., Kiavarz, M., Alavipanah, S. K., Lakes, T., Qureshi, S., 2018: Monitoring and forecasting heat island intensity through multi-temporal image analysis and cellular automata-Markov chain modelling: A case of Babol city, Iran. Ecological Indicators, 91, 155-170.

Khoi, D. D., Murayama, Y., 2010: Forecasting areas vulnerable to forest conversion in the Tam Dao National Park Region, Vietnam. Remote sensing, 2(5), 1249-1272.

Kissinger, G., 2020: Policy responses to direct and underlying drivers of deforestation: examining rubber and coffee in the central highlands of Vietnam. Forests, 11(7), $733-757$.

Landis, J. R., Koch, G. G., 1977: An application of hierarchical kappa-type statistics in the assessment of majority agreement among multiple observers. Biometrics, 363-374.

Losiri, C., Nagai, M., Ninsawat, S., Shrestha, R. P., 2016: Modeling Expansion in Bangkok Metropolitan Region Using Demographic-Economic Data through Cellular AutomataMarkov Chain and Multi-Layer Perceptron-Markov Chain Models. Sustainability, 8(7), 686.

Megahed, Y., Cabral, P., Silva, J., Caetano, M., 2015: Land cover mapping analysis and urban growth modelling using remote sensing techniques in greater Cairo region-Egypt. ISPRS International Journal of Geo-Information, 4(3), 1750-1769.

Mishra, V. N., Rai, P. K., Mohan, K., 2014: Prediction of land use changes based on land change modeler (LCM) using remote sensing: a case study of Muzaffarpur (Bihar), India. Journal of the Geographical Institute" Jovan Cvijic", SASA, 64(1), 111-127.

Mozumder, C., Tripathi, N. K., 2014: Geospatial scenario based modelling of urban and agricultural intrusions in Ramsar wetland Deepor Beel in Northeast India using a multi-layer perceptron neural network. International Journal of Applied Earth Observation and Geoinformation, 32, 92-104.

Mozumder, C., Tripathi, N. K., Losiri, C., 2016: Comparing three transition potential models: A case study of built-up transitions in North-East India. Computers, Environment and Urban Systems, 59, 38-49.

Müller, D., 2004: From agricultural expansion to intensification: Rural development and determinants of land-use change in the Central Highlands of Vietnam. Deutschev Gesellschaft fur Technische Zusammenarbeit (GTZ) GmbH, Eschborn.

Muller, M. R., Middleton, J., 1994: A Markov model of land-use change dynamics in the Niagara Region, Ontario, Canada. Landscape Ecology, 9(2), 151-157.

Ministry of Natural Resources and Environment (MONRE): 2014. Vietnam's fifth national report to the United Nations convention on biological diversity. Reporting period: 2009-2013. MONRE. Hanoi, Vietnam.
Nasiri, V., Darvishsefat, A. A., Rafiee, R., Shirvany, A., Hemat, M. A., 2019: Land use change modeling through an integrated Multi-Layer Perceptron Neural Network and Markov Chain analysis (case study: Arasbaran region, Iran). Journal of Forestry Research, 30(3), 943-957. doi:10.1007/s11676-018-0659-9.

Nguyen, T. T.H., Ngo, T. T. P., 2018: Land use/land cover change prediction in Daknong Province based on remote sensing and Markov Chain Model and Cellular Automata. Viet. Env., 9(3):132-140. doi: 10.13141/jve.vol9.no3.pp132-140.

Nguyen, T.T.H., Doan, M.T., Volker, R., 2018: Applying random forest classification to map land use/land cover using landsat 8 OLI. Int. Soc. Photogramm. Remote Sens, XLII-3/W4, 363-367.

Nguyen, T.T.H., Doan, M.T., Tomppo, E., McRoberts, R. E., 2020: Land Use/Land Cover Mapping Using Multitemporal Sentinel-2 Imagery and Four Classification Methods-A Case Study from Dak Nong, Vietnam. Remote Sensing, 12(9), 1367.

Nouri, J., Gharagozlou, A., Arjmandi, R., Faryadi, S., Adl, M., 2014: Predicting Urban Land Use Changes Using a CA-Markov Model. Arabian Journal for Science and Engineering, 39(7), 5565-5573. doi:10.1007/s13369-014-1119-2.

Ozturk, D., 2015: Urban growth simulation of Atakum (Samsun, Turkey) using cellular Automata-Markov chain and multi-layer Perceptron-Markov chain models. Remote Sensing, 7(5), 59185950.

Pontius Jr, R. G., 2000: Comparison of categorical maps. Photogramm. Eng. Remote Sens, 66, 1011-1016.

Prakasam, C., 2010: Land use and land cover change detection through remote sensing approach: A case study of Kodaikanal taluk, Tamil nadu. International journal of Geomatics and Geosciences, 1(2), 150.

Sang, L., Zhang, C., Yang, J., Zhu, D., Yun, W., 2011: Simulation of land use spatial pattern of towns and villages based on CA-Markov model. Mathematical and Computer Modelling, 54(3-4), 938-943.

Sothe, C., Almeida, C. M. d., Liesenberg, V., Schimalski, M. B., 2017: Evaluating Sentinel-2 and Landsat-8 data to map sucessional forest stages in a subtropical forest in Southern Brazil. Remote Sensing, 9(8), 838 .

Teluguntla, P., Thenkabail, P. S., Oliphant, A., Xiong, J., Gumma, M. K., Congalton, R. G., Huete, A., 2018: A 30-m landsat-derived cropland extent product of Australia and China using random forest machine learning algorithm on Google Earth Engine cloud computing platform. ISPRS Journal of Photogrammetry and Remote Sensing, 144, 325-340.

Wang, W., Zhang, C., Allen, J. M., Li, W., Boyer, M. A., Segerson, K., Silander, J. A., 2016: Analysis and prediction of land use changes related to invasive species and major driving forces in the state of Connecticut. Land, 5(3), 25.

Yirsaw, E., Wu, W., Shi, X., Temesgen, H., Bekele, B., 2017: Land use/land cover change modeling and the prediction of subsequent changes in ecosystem service values in a coastal area of China, the Su-Xi-Chang Region. Sustainability, 9(7), 1204. 